\title{
Safety and Efficacy of Intravenous Ferric Carboxy Maltose in Iron Deficiency Anaemia During Post- partum Period
}

Vineet Mishra, ${ }^{1}$ Priyankur Roy, ${ }^{1}$ Khushali Gandhi, ${ }^{1}$ Sumesh Choudhary, ${ }^{1}$ Rohina Aggarwal, ${ }^{1}$ Shaheen Hokabaj

${ }^{1}$ Institute of Kidney Diseases and Research Centre, B. J. Medical College Campus, Asarwa, Ahmedabad 380016. India.

\author{
ABSTRACT \\ Background: Iron deficiency is the commonest treatable cause of postpartum anaemia. Parenteral iron therapy results in faster \\ and higher replenishment of iron stores and correction of haemoglobin levels with better compliance. Ferric Carboxy Maltose is \\ an effective and a safe option which can be administered intravenously in single total correction dose without any serious adverse \\ effects. The study was done to evaluate the efficacy and safety of Ferric Carboxy Maltose in the treatment of iron deficiency anaemia \\ in post-natal patients. \\ Methods: It was an open, single arm study including 615 women with diagnosis of Iron deficiency anaemia and haemoglobin \\ (Hb) levels between $4 \mathrm{gm} \%$ and $11 \mathrm{gm} \%$ from January 2013 to December 2016. Intravenous Ferric Carboxy Maltose(500-1500mg) \\ was administered and the improvement in haemoglobin levels and iron stores were assessed after three weeks of total dose infusion. \\ Results: Out of the 615 women, 595 women were included in the analysis. Most of the women were in the age group of 27-30 \\ years. Most of the women had mild anaemia as per World Health Organisation guidelines. Mean hemoglobin levels significantly \\ increased over a period of three weeks after Ferric Carboxy Maltose administration. Other parameters like total iron binding \\ capacity, Ferritin and Iron also had a significant improvement after Ferric Carboxy Maltose administration. No serious adverse \\ events were observed after Ferric Carboxy Maltose. \\ Conclusions: Intravenous Ferric Carboxy Maltose was an effective and a safe treatment option for iron deficiency anaemia and \\ has an advantage of single administration of high doses without serious adverse effects. \\ Keywords: Ferric carboxy maltose; haemoglobin;iron deficiency anemia.
}

\section{INTRODUCTION}

Iron deficiency is the most prevalent nutritional deficiency amongst women in the reproductive age group. ${ }^{1}$ Effects of iron deficiency during pregnancy and post-partum period include - fatigue, cardio-respiratory problems, increased chances of infection, reduced immunity, lactation failure, increased post-partum depressive episode, and post-partum hemorrhage. ${ }^{2}$ WHO estimates that, of the 5,29,000 maternal deaths occurring every year, $1,36,000(25.7 \%)$ takes place in India, where two-thirds of maternal deaths occur postpartum, PPH being the leading cause of death. ${ }^{3}$

Intravenous iron dextran may cause allergic reaction and iron sucrose requires repeated doses infusion. Ferric Carboxy Maltose (FCM) has the ability to be injected safely in a single dose as large as $1500 \mathrm{mg}$ in as little as 15 minutes. FCM is cost effective with other positive benefits of fewer hospital visits and improved patient compliance. ${ }^{4}$ This study assessed the efficacy and safety of intravenous FCM in the post-natal womenwith iron deficiency anemia by administering total correction dose (500-1500 mg).

\section{METHODS}

This was an observational study held over a period of 4 years (January 2013 to December 2016). A total of 615 women attending the post-natal clinic at the Institute of Kidney Disease and Research Centre (IKDRC), Ahmedabad were recruited for the study. After explaining about the requirement of administering $\mathrm{FCM}$, its adverse effects, written informed consent were obtained from all the women and attenders. Ethical guidelines were followed 
as advised for human studies and an IRC approval was also obtained.

Women more than 18 years of age, with a diagnosis of iron deficiency anemia ranging between $4 \mathrm{gm} \%$ to 11 gm\% of haemoglobin levels were included in the study. Women excluded from the study had anaemia due to other causes, hemodynamic instability or developed allergic reactions to iron therapy previously.Iron deficiency was diagnosed on parameters like complete blood count $(\mathrm{CBC})$, peripheral blood smear, packed cell volume $(P C V)$, serum ferritin, serum total iron binding capacity (TIBC) and serum iron. Patients were explained about the drug and possible side effects. Twenty women were were excluded from the analysis as they were lost to follow up.

The total required dose of Ferric Carboxy Maltose (FCM) was calculated using Ganzoni formula.

The recommended dose of FCM should not exceed $1500 \mathrm{mg}$ of iron $(30 \mathrm{ml})$ per day. FCM was administered as an infusion diluted in sterile $0.9 \%$ sodium chloride $(\mathrm{NaCl})$ solution. $\mathrm{FCM}$ injection, $500 \mathrm{mg}$ can be diluted with $100 \mathrm{ml} \mathrm{NaCl}$ and administered over 6 minutes. Doses between $1000 \mathrm{mg}$ and $1500 \mathrm{mg}$ require dilution with $250 \mathrm{ml} \mathrm{NaCl}$ and an administration time of 15 minutes. The drug was administered under direct supervision and infusion was immediately stopped in case of any side effects. The women were followed up after three weeks of total dose infusion to assess the status of iron stores and increase in haemoglobin using same parameters as previously mentioned.

\section{RESULTS}

A total of 615 post-partum women who delivered at our tertiary care hospital were included in the study. Most common age group included women between 2730 years of age $(n=237,38.5 \%$ ) (Table1). About $60.3 \%$ $(n=371)$ of women were multigravida and39.7\% $(n=244)$ were primigravida.

\section{Table 1. Distribution according to age $(n=615)$.}

\begin{tabular}{|lr|}
\hline Age (years) & No. of women \\
\hline $19-22$ & $62(10.1 \%)$ \\
\hline $23-26$ & $189(30.7 \%)$ \\
\hline $27-30$ & $237(38.5 \%)$ \\
\hline $31-34$ & $79(12.9 \%)$ \\
\hline $35-38$ & $48(7.8 \%)$ \\
\hline
\end{tabular}

Out of the post-partum women recruited in the study, 425 women $(69.1 \%)$ underwent caesarean section, the commonest indications being previous caesarean and IVF conceived pregnancies; and 190 women delivered by vaginal route $(30.9 \%)$. Most of the women were having moderate anaemia (64.4\%), whereas 87 women (14.1\%) were having severe anaemia and they also responded well to intravenous FCM therapy (Table 2).

\begin{tabular}{lr}
$\begin{array}{l}\text { Table } 2 . \text { Distribution according to degree of anaemia } \\
(\mathrm{n}=615) .\end{array}$ & No. of women \\
\hline Anaemia & $132(21.5 \%)$ \\
\hline Mild & $396(64.4 \%)$ \\
\hline Moderate & $87(14.1 \%)$ \\
\hline Severe & \\
\hline
\end{tabular}

As calculated according to Ganzoni formula, 309 women (50.3\%) required 3 vials of intravenous FCM, for total correction dose infusion. In rest of the women, 2 vials of intravenous FCM was required in 214 women (34.8\%) whereas only 1 vial was required in 92 women (14.9\%).

There was a significant improvement in haemoglobin levels over a period of 3 weeks from mean $\mathrm{Hb}$ of 8.97 \pm 1.05 to $11.34 \pm 0.90$. Other parameters like TIBC, Ferritin and Iron showed marked improvement after FCM administration. The efficacy of the drug in the management of IDA is shown in Table 3.

\begin{tabular}{|c|c|c|c|}
\hline Variables & Pre-values & Post-values & p-value \\
\hline $\begin{array}{l}\text { Hemoglobin } \\
\text { (gm/dL) }\end{array}$ & $8.97 \pm 1.05$ & $11.34 \pm 0.90$ & $<0.001$ \\
\hline PCV & $29.78 \pm 21.20$ & $36.41 \pm 3.01$ & $<0.001$ \\
\hline $\operatorname{TIBC}(\mu \mathrm{g} / \mathrm{dL})$ & $\begin{array}{c}402.57 \pm \\
97.28\end{array}$ & $\begin{array}{c}275.59 \pm \\
47.24\end{array}$ & $<0.001$ \\
\hline $\begin{array}{l}\text { Ferritin(ng/ } \\
\qquad \mathrm{dL})\end{array}$ & $18.30 \pm 16.39$ & $\begin{array}{c}104.10 \pm \\
32.46\end{array}$ & $<0.001$ \\
\hline Iron $(\mu \mathrm{g} / \mathrm{dL})$ & $47.23 \pm 18.87$ & $\begin{array}{c}92.89 \pm \\
26.93\end{array}$ & $<0.001$ \\
\hline
\end{tabular}

No serious life threatening adverse events were reported. Sixteen women had local reactions like itching and irritation at local site while another 19 women reported systemic reactions in the form of giddiness, headache and nausea (Table 4). The sense of wellbeing also improved in all women on follow up, except for 15 woman who felt that they were not being adequately 
treated as oral iron medications were stopped after FCM administration.

\begin{tabular}{lr}
\hline Table 4. Adverse reactions of FCM $(n=615)$. \\
\hline Description & No. of women \\
Local reactions & $16(2.6 \%)$ \\
Systemic reactions & $19(3.1 \%)$ \\
\hline Total adverse reactions & $35(5.7 \%)$ \\
\hline
\end{tabular}

\section{DISCUSSION}

Iron deficiency anemia is a frequent morbidity during pregnancy and post-partum period imposing substantial disease burden and can be very debilitating, especially when caring for a new born. Women having IDA have longer hospital stay, risk of post-partum hemorrhage and need for blood transfusion. Hence, IDA requires a great attention and high quality care. The most reliable parameters to assert IDA is hemoglobin and serum ferritin. The conventional treatment with oral iron therapy and blood transfusion has its own drawbacks. Oral iron intake is limited by gastrointestinal complaints and patient non-compliance. Due to risk of infections, blood transfusions are reserved for most severe cases and particularly in life threatening situations. In addition, an inflammatory reaction can occur, particularly following surgically assisted deliveries and caesarean sections, causing sequestration of iron in the macrophages and thus diminishing the intestinal absorption, so that administrated iron is not available for hematopoiesis. ${ }^{5}$

To overcome these problems, intravenous iron preparations like iron dextran, iron sucrose, FCM are used. Comparison of oral iron versus intravenous iron sucrose has shown a statistically significant increase in the hemoglobin and ferritin level in the intravenous group. However, iron sucrose has its own limitations. ${ }^{6}$ FCM represents a novel iron preparation that overcomes limitation of existing intravenous iron preparation. FCM has a more stable structure as compared to iron sucrose and ferric gluconate. Therefore, large doses can be administered over shorter periods resulting in rapid replenishment of iron stores with fewer administrations. ${ }^{7}{ }^{16} \mathrm{High}$ dose administration of FCM is safe, well tolerated and effective in treatment of IDA also in patients of chronic kidney disease. ${ }^{8}$

In our study, the mean total iron deficit ranged from 500 to $1500 \mathrm{mg}$ against which mean actual elemental iron administered through intravenous FCM was also the same; hence, a total dose correction was administered. After administration of intravenous FCM, the mean haemoglobin levels increased by $2.37 \mathrm{gm} \%$ during follow-up after threeweeks, the results being statistically significant $(p<0.001)$. The parameters also showed increase in TIBC, serum ferritin and serum iron significantly. Our results validated several randomized controlled multicentric trials in post-partum women, where FCM was considered to be very effective in the treatment of IDA. ${ }^{7,8,11,14}$

In another prospective study, intravenous FCM infusion significantly increased $\mathrm{Hb}$ values $(\mathrm{p}<0.01)$ above baseline levels in all women. Increased $\mathrm{Hb}$ values were observed at 3 and 6 weeks post infusion and up to 8 weeks post-infusion. Ferritin values also increased significantly after the infusion. ${ }^{9}$ David et $\mathrm{al}^{10}$, Evstatiev et $\mathrm{al}^{11}$ and Iftikhar et $\mathrm{al}^{12}$ proved that FCM was well tolerated and had better compliance than other iron preparations. The results of our study were consistent with the above mentioned trials. FCM has been shown to be an effective option in the treatment of IDA in multiple studies and it also improves the quality of life. ${ }^{12}$

FCM was well tolerated and was associated with few local and mild systemic reactions but no serious life threatening allergic reactions were reported. FCM is a stable non-dextran containing complex, with very low immunogenic potential and therefore not predisposed to anaphylactic reactions. ${ }^{13}$ Thus, FCM was a safe and an effective treatment option for IDA. Most of the studies have shown that FCM is relatively safe with a low incidence of adverse effects. Most common adverse effects noted were nausea, diarrhea, bloating, abdominal pain, headache and rashes. ${ }^{14}$ Serious adverse reactions noted were unrelated to FCM administration. ${ }^{15}$

\section{CONCLUSIONS}

Our study showed that intravenous Ferric Carboxy Maltose offers rapid replacement of haemoglobin and iron storage in body without significant adverse effects during the post-partum period.

\section{REFERENCES}

1. Jain G, Palaria U, Jha SK. Intravenous iron in postpartum anemia. J Obstet Gynecol India. 2013;63(1):45-8.[Full Text]

2. Kaur K. Anaemia 'A silent killer' among women in India: Present scenario. Euro J Zool Res. 2014;3(1):32-6.[ijrcog]

3. Kalaivani K. Prevalence and consequences of anaemia in pregnancy. Indian J Med Res. 2009;130:627-33.[medind. 
in]

4. Klaire E, Nancy T, Andrea A, Atif K, Shahed A. Efficacy and safety profile of single dose intravenous ferric carboxymaltose in the management of renal anemia:asingle center experience. Nephrol Dial Transplant. 2013;28(1):363-4.[medind.nic.in]

5. Pfenniger A, Schuller C, Christoph P, Surbek D. Safety and efficacy of high dose intravenous iron carboxy maltose vs iron sucrose for treatment of postpartum anemia. J Perinat Med. 201240(4):397-402.[PubMed]

6. Bhavi SB, Jaju PB. Intravenous iron sucrose $\mathrm{v} / \mathrm{s}$ oral ferrous fumarate for treatment of anemia in pregnancy. A randomized controlled trial. BMC Pregnancy Childbirth. 2017; 17:137.[Full Text]

7. Breymann C, Gliga F, Bejenariu C, Strizhova N. Comparative efficacy and safety of intravenous ferric carboxymaltose in the treatment of postpartum iron deficiency anemia. Int J Gynaecol Obstet. 2008;101(1):67-73.[PubMed]

8. Vikrant S, Parashar A. The safety and efficacy of high dose ferric carboxymaltose in patients with chronic kidney disease: asingle center study. Indian J Nephrol. 2015;25(4):213-21. [PubMed]

9. Froessler B, Collingwood J, Hodyl NA, Dekker G.Intravenous ferric carboxymaltose for anaemia in pregnancy. BMC Pregnancy Childbirth. 2014;14:115 [pubmed]

10. David BB, Lawrence TG. Experience with intravenous ferric carboxy maltose in patients with iron deficiency anemia.Ther Adv Hematol. 2014;5(2):48-60. [http:// journals.sagepub.com]
11. Evstatiev M, Iqbal T, Khalif IL, Stein J, Bokemeyer B. FERGI Study Group: A randomized controlled trial on FCM for IDA in inflammatory bowel disease. Gastroenterology. 2011;141(3):846-53.[PubMed]

12. Iftikhar H, Jessica B, Angelia B, Todd A, Andy H, David BB. Direct comparison of the Safety and Efficacy of FCM vs Iron Dextran in Patients with Iron Deficiency Anemia. Anemia. 2013;169107,10.[PubMed]

13. Friedrisch JR, Cançado RD. Intravenous ferric carboxymaltose for the treatment of iron deficiency anemia. Revista Brasileira de Hematologia e Hemoterapia. 2015;37(6):400-5. [Full Text]

14. Charytan C, Bernardo M, Koch T, Butcher A, Morris D, Bregman DB. Intravenous ferric carboxy maltose versus standard medical care in the treatment of iron deficiency anemia in patients with chronic kidney disease: A randomized, active-controlled, multicenter study. Nephro Dial Transplant. 2013; 28:953-64.[PubMed]

15. Wolf M, Koch TA, Bregman DB. Effects of iron deficiency anemia and its treatment on fibroblast growth factor 23 and phosphate homeostasis in women. J Bone Mineral Research. 2013;28(8):1793-803.[Full Text]

16. Joshi SD, Chikkagowdra S, Kumar VCM. Comparative study of efficacy and safety of intravenous ferric carboxy maltose versus iron sucrose in treatment of postpartum iron deficiency anemia. Int J Reprod Contracept Obstet Gynecol 2016;5:2566-70 [Full Text] 